\title{
Gestión de riesgos de colecciones. Dos casos de estudio en Tunja, Boyacá ${ }^{1}$ Risk collections manage- \\ Carreño, C.A. (2014). Gestión de riesgos de colecciones. Dos casos de estudio en Tunja, Boyacá, Designa, 3(1), 32 - 57.
}

\section{Palabras clave:}

Conservación de bienes culturales, edificio del museo, prevención de desastres

\section{Key words:}

Cultural property preservation, museum buildings, disaster prevention.

Recibido: 27-jun- 2014 Aceptado: 26-sep- 2014

\footnotetext{
* Profesional en Conservación y Restauración de Bienes Muebles, Universidad Externado de Colombia. Coordinador de la Red Departamental de Museos de Boyacá, perteneciente al Sistema Departamental de Cultura de la Secretaría de Cultura y Turismo de Boyacá. conservacion.restauracion76@gmail.com
}

\footnotetext{
${ }^{1}$ Estudio comparativo de los resultados arrojados por la investigación para la aplicación y adaptación de la Metodología de Gestión de Riesgos de Colecciones (ICCROM-UNESCO 2009), para la Casa Museo del Escribano Don Juan de Vargas (2011) y la Casa Museo del Fundador Gonzalo Suárez Rendón (2013) en Tunja, Boyacá. Esta es la primera experiencia regional de este tipo en Colombia. En el primer caso se trató del tema de trabajo de grado del autor para optar por el título de Profesional en Conservación y Restauración de Bienes Muebles de la Facultad de Estudios del Patrimonio Cultural de la Universidad Externado de Colombia. Por su parte, el segundo fue financiado por la Alcaldía Mayor de Tunja.
}

\section{Resumen:}

El presente artículo de reflexión derivada de Investigación relaciona los resultados obtenidos en dos investigaciones realizadas por el autor para la aplicación, por primera vez en Colombia, de la Metodología de Gestión de Riesgos en Colecciones (ICCROM-UNESCO 2009) en dos museos regionales: la Casa del Escribano Don Juan de Vargas (2011) y la Casa del Fundador Gonzalo Suárez Rendón (2013).

Se destaca la importancia de la metodología en cuestión para renovar la mirada de la ciencia de la conservación de colecciones en museos. Como punto de partida se toma el concepto de gestión de riesgos, para exponer luego los resultados a la luz de las fases metodológicas propuestas. De acuerdo con dichos resultados, se trata de dos entidades museales amenazadas tanto por agentes ambientales como antropogénicos que de no ser corregidos a tiempo atentan contra el sistema integral de valor custodiado. Se termina con una serie de conclusiones que giran en torno a la efectividad de la metodología implementada para los casos de aplicación, sus necesidades de adaptación al contexto local y la preocupante situación actual de la conservación de acervos museológicos en Colombia.

\section{Abstract}

This paper shows the results of two surveys conducted by the author for the first ever implementation in Colombia of the Risk Collections Management (ICCROMUNESCO 2009) in two regional museums such as Casa del Escribano Don Juan de Vargas (House of the Scribe Juan de Vargas) in 2011 and Casa del Fundador Gonzalo Suárez Rendón (House of the Founder Gonzalo Suárez Rendón) in 2013.

The importance of this methodology to renew the view of the collections conservation science in museums is highlighted. Initially, the concept of risk management is approached, then the research results from the perspective of the methodological phases proposed are explained. The results demonstrate that the museums mentioned are jeopardized by both environmental and anthropogenic agents which if not properly dealed betimes might represent a threat for the whole system of values being preserved. Finally, the conclusions regarding the effectiveness of the methodology applied, its requeriments for adaptation into the local context and the alarming situation of the museological assets preservation in Colombia are listed. 
Los problemas que en términos de conservación presentan las colecciones de objetos han sido motivo de reflexión para la disciplina de la conservación y restauración de bienes muebles y la han llevado a contemplar la necesidad de prevenir antes que en intervenir. Dentro del devenir de las estrategias utilizadas para tal fin, la Metodología de Gestión de Riesgos en Colecciones (2009), propuesta por el ICCROM y la UNESCO ${ }^{2}$, aparece en la actualidad como una posibilidad para comprender las situaciones que podrían presentarse en términos de riesgo.

\section{INTRODUCCIÓN}

Sus aportes radican en una nueva postura respecto a lo que se entiende por colección y su relación directa con el contexto donde se encuentra. Además, brinda referentes para fundamentar su valor como conjunto y otorga herramientas destinadas a la identificación de determinadas causas y la proyección conceptual de las posibles consecuencias de estas en caso que se presenten, lo cual involucra el concepto de "administración" como objetivo para quienes custodian colecciones con potencial patrimonial. De tal modo, se busca bloquear riesgos, mitigar daños probables y lograr el máximo de "productividad cultural" del conjunto de objetos.

Este método sistemático implica, más que la aplicación de pasos predefinidos, un proceso reflexivo y lógico para establecer claramente el contexto; identificar, analizar, evaluar, tratar y monitorear los riesgos identificados con el fin de minimizar las posibilidades de pérdida de valor, tanto de objetos como del conjunto. Además, apunta hacia la concientización de todos y cada uno de los entes involucrados en 
cuanto se refiere a la importancia

cultural de la colección y el carácter fundamental de la salvaguarda de sus valores. Esto implica un cambio en la mentalidad del custodio de manera que articule la conservación preventiva como eje fundamental en sus prácticas y procesos cotidianos en lugar de concebirla como una actividad separada o complementaria. Solo de este modo se logra concretar la verdadera gestión de riesgos en el plano institucional.

La aplicación de esta metodología es nueva en el contexto colombiano y dentro del ejercicio académico apenas se está iniciando su conocimiento.

El presente documento expone los resultados de su implementación por primera en dos casos de estudio en Boyacá: la Casa Museo del Fundador Gonzalo Suárez Rendón y la Casa Museo del Escribano Don Juan de Vargas, ambos custodios de importantes acervos museológicos dentro del sistema integral de valor portado por el centro histórico de la ciudad de Tunja, pero con distinta conceptualización de uso.

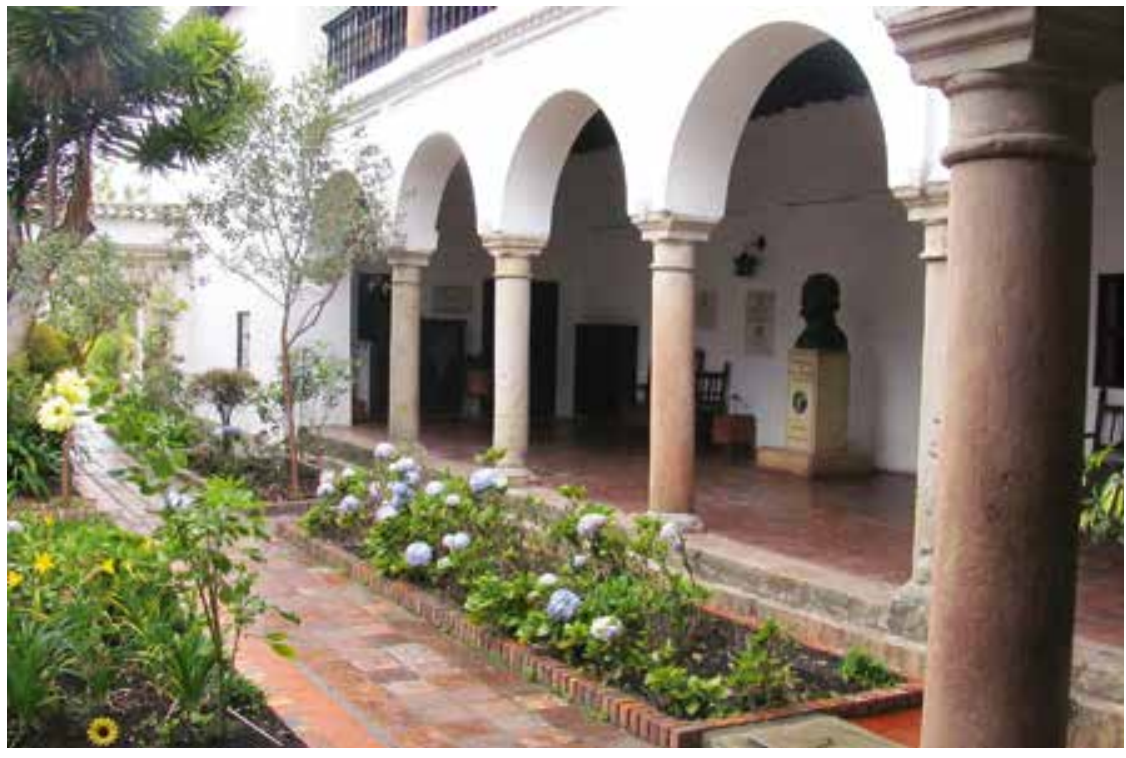

Figura 1. Casa Museo del Fundador Gonzalo Suárez Rendón Fuente: autor

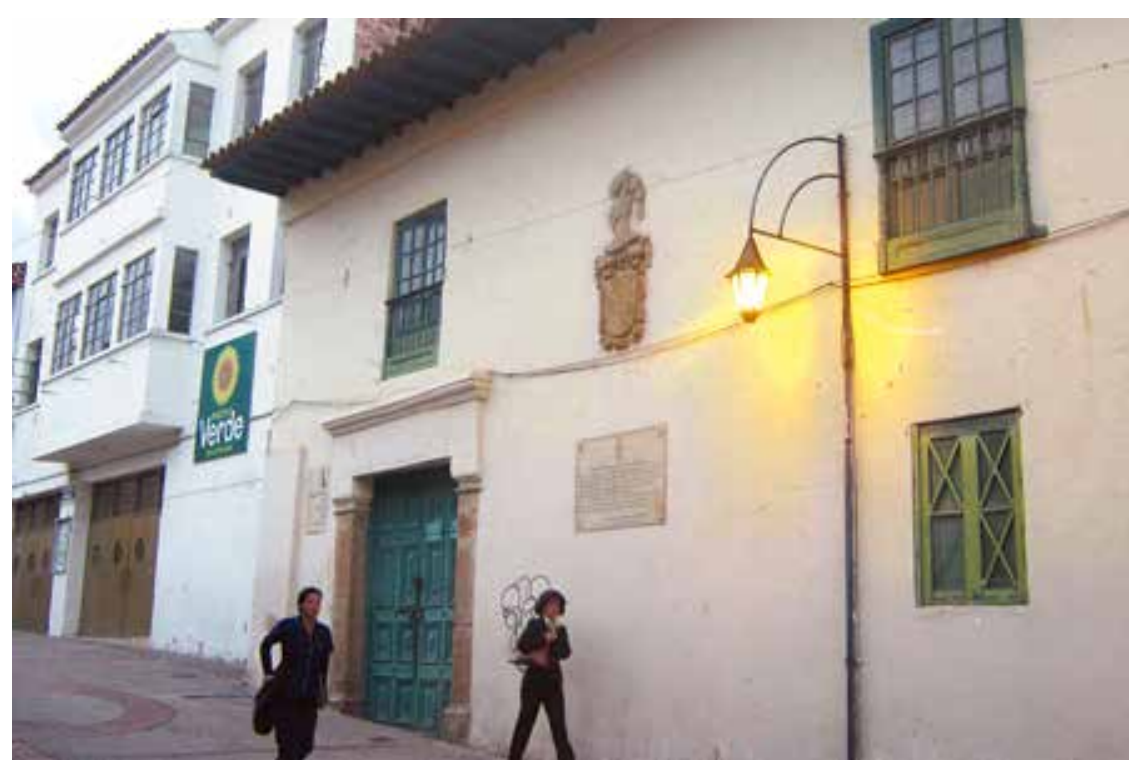

Figura 2. Casa Museo del Escribano Don Juan de Vargas Fuente: autor 


\section{GESTIÓN DE RIESGOS}

Al hablar de Gestión de

Riesgos desde la Conservación de Bienes Muebles, es necesario entender su conceptualización como una construcción aún en proceso, pues su aparición en el ámbito de la conservación integral de colecciones es relativamente reciente. $\mathrm{Al}$ respecto, Cardona (2001) comenta:

La concepción del riesgo y

la terminología asociada a su definición no solo ha variado con el tiempo, también ha variado desde la perspectiva disciplinar desde la cual se ha abordado su noción. Esto significa que a pesar del refinamiento con el que se le trata desde los diferentes ámbitos del conocimiento, no existe en realidad una concepción que se pueda decir unifique las diferentes aproximaciones o que recoja de manera consistente o coherente los diferentes enfoques ( $p .1)$.

Si se tiene en cuenta que las colecciones están inmersas en un contexto cuyos niveles afectan de una u otra manera la estabilidad de los objetos que las componen, la denominada gestión de riesgos propone una mirada para abordar la intervención desde los niveles de la protección. Así, se plantea como una estrategia que parte de la intervención del foco del riesgo y no del posible resultado del mismo. Dicha estrategia diferencia el concepto de "riesgo" del de "indicador", constantemente confundidos al abarcar el problema desde la conservación preventiva tradicional.

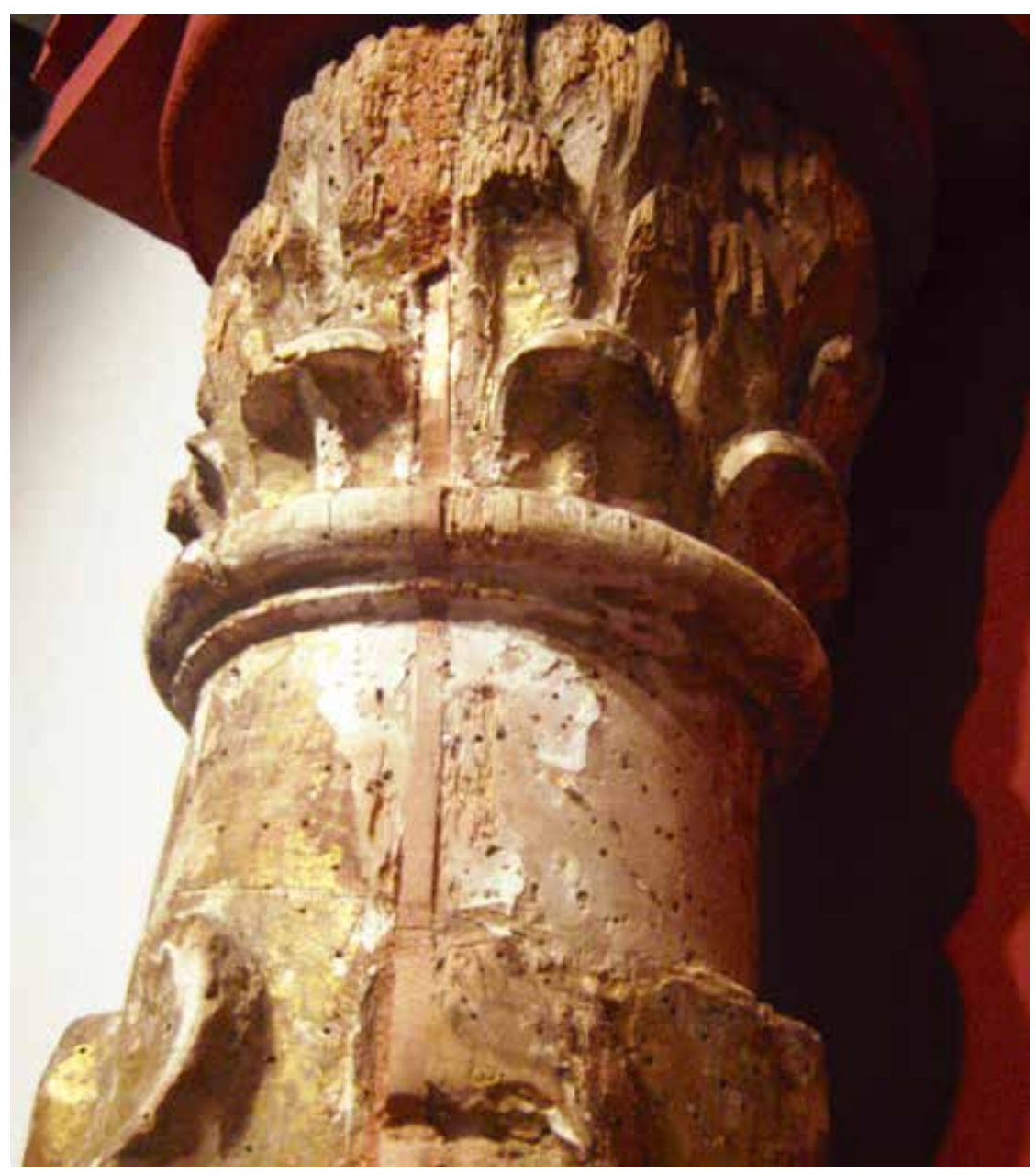

Figura 3. Deterioro por xilófagos - colección de la Casa Museo del Escribano Don Juan de Vargas. Fuente: autor. 
La palabra "riesgo" en conservación siempre ha estado relacionada a peligros inminentes, "generalmente relacionados a desastres naturales, catástrofes como el fuego, situaciones como los robos - simplemente la caída de una pieza" (Garnica, 2010, p. 7). Sin embargo, la discusión generada en torno a la valoración de los bienes muebles ha llevado a reevaluar el sentido de dicha palabra, pues los objetos no solo poseen cualidades formales de materia y forma que los cotizan en términos de valores numéricos, sino que además son depositarios de "su autenticidad, su originalidad, su singularidad" (Garnica, 2010, p. 8). Estas variables, desde la conservación, implican una evaluación de los riesgos en términos de la colección como contexto conceptual inmediato, es decir, que el valor de una pieza esta íntimamente ligado a sus posibilidades y su relevancia discursiva dentro de la narrativa y el sistema dialéctico del que haga uso el museo como contenedor: "Bajo esa línea de pensamiento (...) los bienes incrementarían su valor a través de las investigaciones al añadir información, 'enriqueciendo' así la colección" (Garnica, 2010, p. 8).
Si se conoce y comprende lo anterior, se observa que la efectividad de la gestión de riesgos y su aporte al campo de la conservación de colecciones radica en tomar como punto de partida una evaluación de los valores implícitos en el objeto. Es preciso considerar que el deterioro material trae consigo la posible disminución de dichos valores en términos comunicantes, cuyo límite sería la pérdida total. La gestión se entendería entonces como una estrategia planteada desde la conservación, encaminada a bloquear una pérdida total. Al respecto, Garnica comenta:

Es allí donde actúa la conservación, tratando de evitar los cambios "negativos" en
la materia, elaborando las directrices para la conservación preventiva, proclives a
mantener el cambio "tan bueno" como nos sea posible. Luego, desarrollar métodos
para consolidar el cambio o incluso restaurar la condición material de lo que era
antes. Esto sería la optimización del valor de las colecciones (2010, p. 8).
relación con los peligros que podrían generar una pérdida de valor, existen varias
sibilidades para evaluar su incidencia. Entre estas, el modelo predictivo propuesto por Stephan Michalski en su trabajo sobre la preservación de colecciones pareciera ser el más lógico y coherente con los conceptos básicos de la gestión de riesgos.

Según Garnica (2010), el modelo propuesto por Michalski se piensa como una forma de prever los riegos antes de que estos aparezcan, a partir de una evaluación que sigue un sistema de acción orientado a:

1. Decidir las prioridades y evaluar los riegos.

2. Reducir las pérdidas y el deterioro en los próximos 100 años o más, mediante la medición de la probabilidad de pérdida basada en el deterioro progresivo y acumulativo de las colecciones, el cual es provocado por los agentes involucrados e identificados. 
3. Clasificar los riesgos de las colecciones por medio del sistema de Clasificación de causas, elaborado por el ICC (Instituto Canadiense de Conservación) y que describe 11 agentes de deterioro: fuerzas físicas, robos y vandalismo, disociación, fuego, agua, plagas, contaminantes, luz visible, radiación ultravioleta $e$ infrarroja, temperatura incorrecta, humedad relativa incorrecta.

En este punto se relaciona la vulnerabilidad de la colección, su jerarquización de valor y el peligro que representa cada uno de los agentes, para establecer así una escala de importancia de los mismos.

\section{Comprometer a todos los}

funcionarios y las instancias del museo - la institución para contrarrestar la incidencia negativa de los riesgos en la colección. En este sentido, se sigue el concepto de responsabilidad preventiva y se evita su fragmentación.

\section{Plantear un ciclo de preservación} de la colección a partir de distintas actividades.

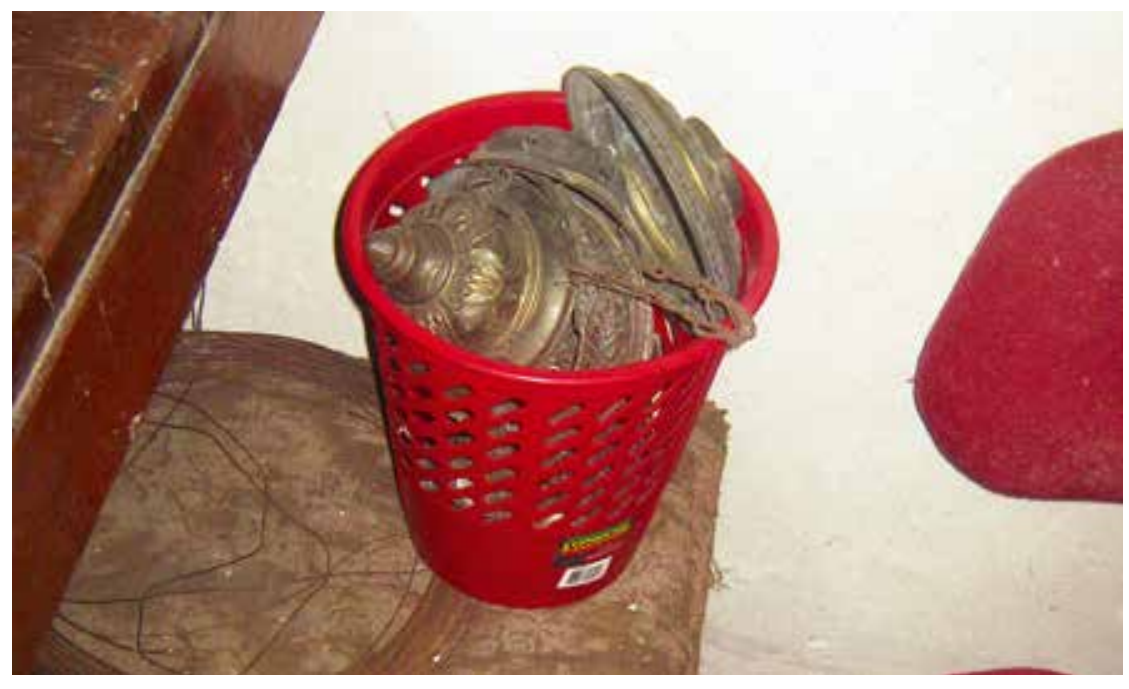

Figura 4. Riesgo por sistema de almacenaje. Casa Museo del Escribano Don Juan de Vargas. Fuente: autor

Este modelo, según la metodología de gestión de riesgos planteada por el ICC, el ICCROM y el ICN (Instituto Holandés para el Patrimonio Cultural), debe pasar por varias etapas:

$1^{\text {a }}$. Reconocimiento del contexto. Se consignan todos los componentes de la institución, entendiéndola como un sistema articulado, que afectarían directamente el sistema de valor de la colección.

$2^{a}$. Identificación de los riesgos. Sistemáticamente se recopila información que permita predecir los riesgos, determinar los datos visibles e invisibles y documentar fotográficamente las observaciones a que haya lugar. Sobre esta etapa dice Michalski: "Exige sentido común, un poco de inteligencia y una buena ojeada (...) aguzar el sentido práctico pero también la imaginación, ya que es preciso imaginar todo lo que saldría mal" (citado por Garnica, 2010, p. 9).

$3^{a}$. Planificación de las acciones a seguir en aras de mejorar las condiciones de conservación. Se plantean cinco etapas para la reducción de los riesgos, "encontrando soluciones particulares y luego soluciones comunes" (Garnica, 2010, p. 9). 
Los múltiples métodos utilizados por

los museos para reducir los riesgos que amenazan sus colecciones pueden "reagruparse en cinco etapas: evitar, impedir, detectar, reaccionar, recuperar - tratar" (Garnica, 2010, p. 10).

De tal modo se logra:

- Evitar las fuentes y los elementos que atraen al agente.

- Impedir que el agente llegue a la colección (si la etapa previa no ha sido efectiva).

- Detectar al agente en el museo (si las dos etapas anteriores no han sido efectivas).

- Reaccionar si se detecta la presencia del agente (para validar la etapa de detección).

- Recuperar y tratar la parte de la colección afectada por el agente (esta etapa involucra procesos de restauración e identificación de lo que no funcionó, como también una previsión de mejorías).
Según Garnica (2010), las primeras cuatro etapas tienen que ver con la prevención del deterioro, en tanto la última se relaciona con la conservación curativa y la restauración, las cuales son "necesarias en caso de que las etapas preventivas hayan fracasado (...) cada etapa tiene un papel que desempeñar y una gestión eficiente implica un justo equilibrio de las cinco etapas" (p. 10).

\section{ESTABLECIMIENTO DEL CONTEXTO}

\section{El contexto para ambos casos de estudio es el centro histórico de}

Tunja, cuyas características geográficas, geomorfológicas, ambientales y socioculturales determinan el espacio físico y humano que contiene y da sentido a las colecciones. Es un detonante de memoria, un referente espacio-temporal y un significante.

\section{Contexto geográfico}

La gestión de riesgos implica, desde su perspectiva investigativa, reconocer el caso de estudio como resultado de su entorno geográfico inmediato, que para este caso es Tunja. De tal modo, se delimita la mirada desde la "razón dialógica" (Salas, 2005) que interviene en la relación inmueble-ciudad como una consecuencia comunicativa entre las partes y exige una profundización acerca de la vinculación entre ellas.

Por su ubicación, Tunja se constituye en un eje importante de vías de tránsito hacia Bogotá, Santander, Casanare y los departamentos del noreste de Colombia. 
Geográficamente se encuentra sobre una pequeña meseta de la Cordillera Oriental perteneciente al sistema montañoso de Los Andes, denominada por el Instituto Geográfico Asustín Codazzi como unidad morfológica del altiplano cundiboyacense, a los 0.5 grados, 32 minutos y 7 segundos de latitud norte y 73 grados, 22 minutos y 0.4 segundos de longitud oeste. El casco urbano se encuentra ubicado a una altura aproximada de 2775 m.s.n.m., en un piso térmico frío con una temperatura promedio anual de 18 grados centígrados, humedad relativa del 56\%, precipitación media anual de $634 \mathrm{~mm}$, velocidad de vientos de ESE de $13 \mathrm{Km} / \mathrm{h}$ y presión atmosférica de $1023.4 \mathrm{mb}$, según datos del Clopad ${ }^{3}$.

Sus límites políticos son:

- Norte: Motavita, Cómbita, Oicatá, Chivatá y Soracá.

- Oriente: Oicatá, Soracá y Chivatá.

- Sur: Boyacá, Ventaquemada y Chivatá.

- Occidente: Samacá, Sora y Cucaita.

Según el Clopad, las características topológicas, de suelos, geológicas y geomorfológicas de la ciudad la han hecho vulnerable ante amenazas de tipo natural, básicamente aquellas asociadas con factores climáticos como erosión, inundaciones y deslizamientos. Además, por estar cerca a superficies tectónicas críticas es susceptible de sufrir movimientos de tierra que afecten la infraestructura urbana, lo cual representa la principal preocupación de las autoridades.

\section{Contexto social}

La ciudad cuenta con una población urbana de 181.407 personas según datos del Censo 2005 (proyectado a 2013) realizado por el Departamento Administrativo Nacional de Estadística (DANE). Tiene 102 establecimientos de educación básica y media, siete de formación tecnológica y profesional y 20 de formación para el trabajo y el desarrollo humano.

${ }^{3}$ Comité Local para la Prevención y Atención de Desastres, dependencia de la Alcaldía de Tunja.
Su historia la hace contenedora de un gran número de bienes muebles e inmuebles de carácter patrimonial, ubicados en su mayoría en el denominado centro histórico, dinamizados por manifestaciones inmateriales que los utilizan, como son el 
${ }^{4}$ Entrevista realizada el 14 de febrero de 2012 a Julio Emiro López Lizarazo, quien para el año 2011 era el Secretario de Cultura y Turismo de la Alcaldía Mayor de Tunja.

${ }^{5}$ Según lo expresado por Julio Emiro López Lizarazo en la misma entrevista.

${ }^{6}$ Entrevista realizada el 20 de febrero de 2012 a Francisco Pulido, quien para el año 2011 era el Secretario de Educación de la Alcaldía Mayor de Tunja.
Aguinaldo Boyacense, la Semana Santa, las Romerías de la Virgen del Milagro y del Señor Caído, entre otras. Dicho patrimonio ha sido empleado por las autoridades municipales y departamentales, a través de sus secretarías de cultura y turismo, como dinamizadores del turismo regional, nacional e internacional. En este sentido, se ha recurrido a estrategias de mercado que si bien no han logrado los objetivos previstos a corto plazo han motivado las visitas de turistas "de todos los lugares de Colombia y extranjeros, que vienen en busca de conocer gran parte del legado de la cultura colonial e indígena que guarda el territorio" ${ }^{4}$.

Las mayores afluencias turísticas se presentan en Semana Santa, las romerías de la Virgen del Milagro, el Aguinaldo Boyacense y el Festival Internacional de la Cultura, cuando la población flotante que circula en el centro histórico para visitar los museos e iglesias coloniales llega al $98 \% 5$.

Otra forma de dinamización del patrimonio mueble e inmueble se presenta, según el Secretario de Educación de Tunja, Francisco Pulido ${ }^{6}$, mediante su utilización como herramienta pedagógica: "el gran acervo cultural de la ciudad convierte a las iglesias y los museos del centro histórico en espacios pedagógicos complementarios de los que hacen uso los colegios para organizar permanentes visitas guiadas". En el caso de la Casa Museo del Escribano, son tres visitas al mes, con una participación de alrededor de 60 niños y un profesor acompañante. Finalmente, cabe mencionar el uso cotidiano de carácter religioso que aún se da a los bienes muebles de iglesias como Santa Bárbara, San Ignacio, Santo Domingo, San Francisco y Las Nieves, entre otras. 


\section{Público}

Luego de un trabajo constante efectuado durante doce años en los museos casos de estudio ${ }^{7}$, de entrevistas a los funcionarios, del análisis realizado a sus libros de visitantes y de la relación de boletas vendidas, se estableció que los públicos de sus exposiciones poseen características similares. Fue entonces posible manejar promedios y resultados iguales para ambos casos, además de identificar la relación dialéctica que para los visitantes tienen las dos visitas posibles.

Según los datos obtenidos, un $81.2 \%$ de los visitantes por mes en los últimos diez años han sido estudiantes de primaria y secundaria de colegios. Este porcentaje es seguido por un $10.15 \%$ de turistas provenientes de otras regiones del departamento, del país y del extranjero. Luego, con $7.61 \%$ se encuentran las visitas de estudiantes universitarios y en último lugar, las de investigadores, con un $1.01 \%$.

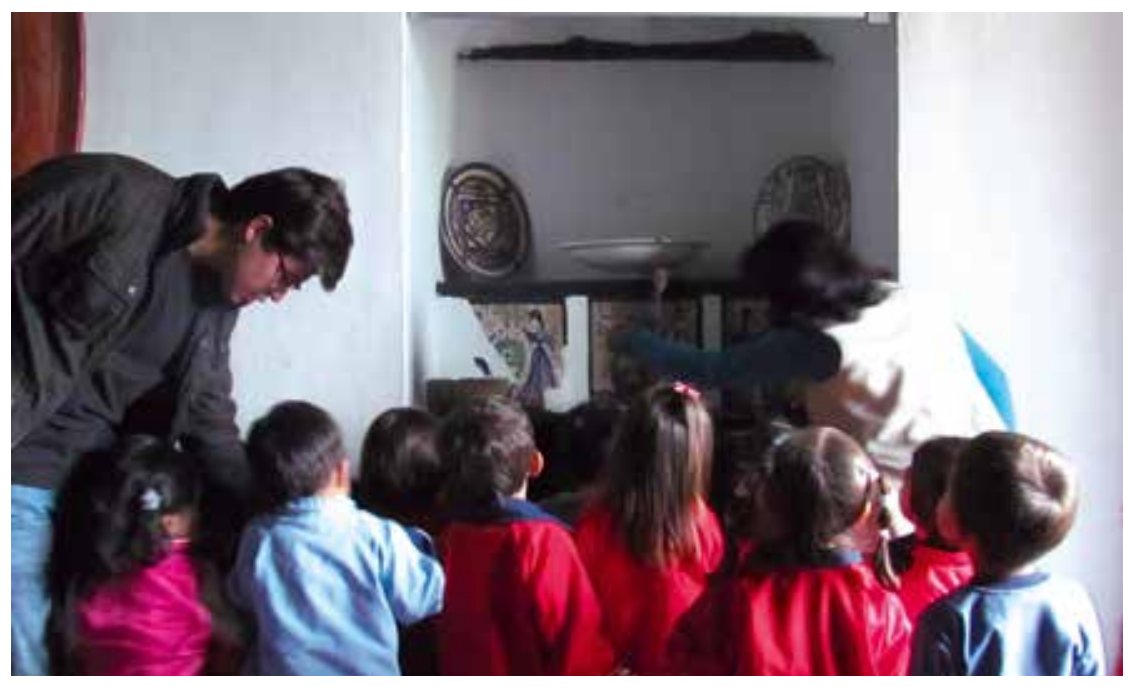

Figura 5. Visitas guiadas para público infantil en la Casa del Fundador. Fuente: autor 
Ambos museos realizan actividades de sensibilización y apropiación de la historia colonial de Tunja a partir de visitas guiadas, dirigidas a particulares y a instituciones educativas. A su vez, la Red de Museos de Tunja, órgano de la Secretaría de Cultura y Turismo de la Alcaldía Mayor, los incluyó en la programación lúdica de la Noche de los Museos, evento que además de las visitas ofrece dinámicas complementarias como conciertos, recitales $y$ cuentería.

\section{Contexto histórico, cultural y} museológico

Tunja fue fundada el 6 de Agosto de 1539 por el Capitán Gonzalo Suárez Rendón, el día en que la islesia Católica, Apostólica y Romana celebra la Transfiguración del Señor y un año después de haberse fundado Santa fe.

El Acta de Fundación fue redactada por el primer Escribano Real que tuvo la ciudad, Don Domingo de Asuirre, y su copia se encuentra actualmente en el Archivo Histórico Regional de Boyacá, en el tomo Actas del Cabildo.
La ciudad fue uno de los centros artísticos y culturales más importantes del entonces Nuevo Reino de Granada. Actualmente, guarda un acervo artístico de obras coloniales distribuidas en distintos espacios del centro histórico, como los templos de Santa Bárbara, Santo Domingo, San Francisco y San Laureano, al igual que las dos únicas casas-museo: la del Capitán Gonzalo Suárez Rendón y la del Escribano Don Juan de Vargas. Estas presentan en sus artesonados y paredes ejemplos relevantes de pintura mural que permiten comprender, junto al mobiliario, la pintura y demás objetos de las colecciones, las lógicas de decoración arquitectónica doméstica que presentaron las casas de personajes ilustres del período de dominación hispánica.

\section{Los personajes}

Ambos casos de estudio fueron residencia de importantes personajes de la historia colonial tunjana. Pero curiosamente, al momento de investigarlos ninguno contaba con una infografía consistente que permitiera establecer con suficiente amplitud la vida y obra de sus residentes, de tal forma que se incrementara el valor histórico del edificio en su condición de soporte del sistema integral de valor cultural custodiado por los correspondientes acervos museológicos.

\section{El trabajo desarrollado llevó a redescubrir la riqueza que en términos de fuentes} primarias se encuentra en distintos archivos: el General de la Nación, el Histórico Regional y el General de Indias (Sevilla, España). Se transcribieron más de tres mil folios que permitieron incrementar la información, tanto del Capitán Suárez Rendón como del Escribano de Vargas Matajudíos. Los datos recolectados representaron la base para comenzar a incrementar los valores culturales de ambos casos, además de brindar mayores elementos para nuevos guiones museográficos.

\section{Los inmuebles}

Ambas casas se encuentran ubicadas en el centro histórico, a pocos metros de distancia entre sí. Son referentes indiscutibles de la lectura urbana, estética y simbólica del lugar, además de haberse convertido en sitios visibles de común manejo dentro de la cotidianidad ciudadana. 
Son de los pocos vestigios todavía existentes del desarrollo arquitectónico de la ciudad, plasmado en el plano original de $1623^{8}$ que reposa en el archivo del palacio arzobispal de Tunja y del cual se han derivado varias investigaciones. Entre estas se destaca la llevada a cabo por la historiadora Magdalena Corradine Mora, Vecinos y Moradores de Tunja, 1620 - 1623, en que se relaciona el mencionado documento junto al Censo realizado en Tunja en 1620, que según la autora.

Son los más antiguos de Colombia, porque los planos de reparto de solares de la fundación de Villa de Leyva de 1572 y 1582 no cuentan por tratarse solo de solares, en el caso de Tunja si se dibujan las casas e iglesias además de las calles y otros aspectos de carácter arquitectónico, como el atrio de la Catedral, las fuentes de agua o la cruz de piedra, y se señalan los propietarios o poseedores de las casas para ese momento (Corradine, 2009, p. 130).

El plano muestra 13 de las 14 iglesias construidas en la Colonia, seis conventos y grandes mansiones de caballeros peninsulares, que hicieron tallar en piedra sus blasones en las portadas Platerescas y Renacentistas, punto central de atracción de las fachadas; se dice que en la América Hispana, fue la ciudad que ostentó

${ }^{8}$ Cuyo autor, según investigadores como Gustavo Mateus Cortés, Javier Ocampo López y Magdalena Corradine, pudo ser Francisco Tenorio de Castro. el mayor número de escudos, que eran sin lugar a dudas símbolo de jerarquía, posición de patronato y piedra fundamental de quienes tenían una jurisdicción o encomienda, cabildantes de primer orden, justicias mayores, procuradores, alcaldes ordinarios, o gobernadores (Mateus, 1995, pp. 14-15).

Los valores formales y tecnológicos de las viviendas han sido descritos por investigadores como Gustavo Mateus Cortés, Marco Dorta, Francisco Gil Tovar, Alberto Corradine y Germán Téllez, entre otros. Sus apreciaciones y publicaciones han aportado de manera significativa a la valoración de estos edificios, los cuales han entrado de manera contundente a la memoria arquitectónica del país. 
Del sistema integral de valor cultural de ambos inmuebles hace parte importante el conjunto de superficies arquitectónicas decoradas, especíicamente los zócalos, paredes y artesonados, pues presentan importantes vestigios de pintura mural que data de los siglos $X V I, X V I I$ y XVIII. Estas representaciones evidencian, a partir de su interpretación iconológica, la forma de pensar de los ilustrados de la época.

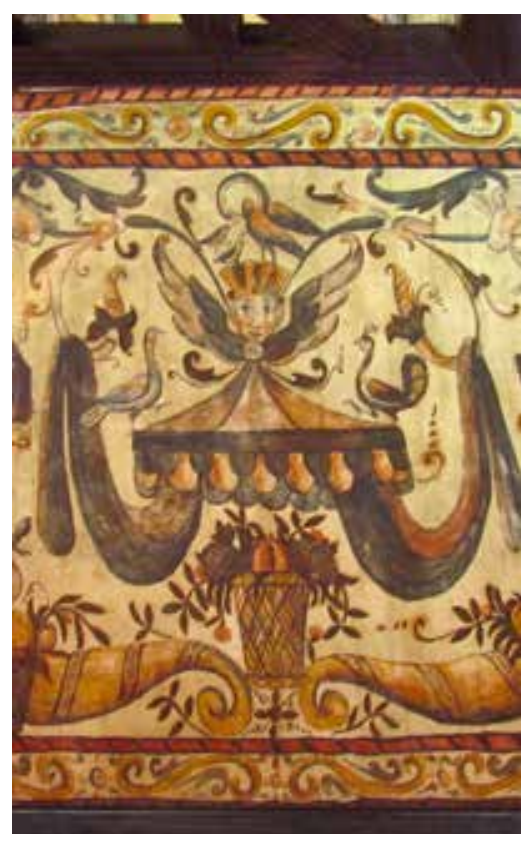

Figura 6. Detalle de pintura mural - Casa Museo del Fundador. Fuente: autor
Los inmuebles han sido objeto de restauraciones y adecuaciones que, por un lado, han favorecido la recuperación y conservación de gran parte de los valores, aunque por otra parte, han transformado los espacios y las lógicas de circulación originales en los espacios internos.

\section{Las instituciones}

Ambas instituciones pertenecen legalmente a la Alcaldía Mayor de Tunja. Sin embargo, mientras la Casa del Fundador existe como museo desde finales de la primera mitad del siglo XX, cuando a partir del Decreto 1998 de 1946 el entonces presidente de Colombia, Mariano Ospina Pérez, la declaró monumento nacional, para la Casa del Escribano no existen documentos legales que le atribuyan una función museal, aunque en el imaginario colectivo lo ha tenido desde su "creación" en la década de 1960 por parte de Luis Alberto Acuña, cuando el maestro era presidente del Instituto de Cultura Hispánica.

La situación de ambas entidades no ha interrumpido ni alterado su función como referentes de memoria dentro de la cotidianidad de la ciudad. No obstante, se observa más sólida la posición de la Casa del Escribano al mantener una "independencia" entre la zona de oficinas administrativas (Fondo Mixto de Cultura de Boyacá) con respecto a la exposición. En la Casa del Fundador esta división se diluye por el uso inadecuado de los espacios expositivos por parte de las dependencias que allí funcionan, tales como la Secretaría de Cultura y Turismo de la ciudad, la Academia Boyacense de Historia y el Consejo Superior de la Policía.

\section{La colección y la exposición}

Una de las diferencias fundamentales entre los casos de estudio son sus colecciones y la forma en que estas se articulan. Ambas presentan características particulares que obedecen a los fines originales concebidos por quienes consolidaron los museos. 
Aun así, algo tienen en común y es la importancia de cuanto custodian. Por un lado, en sus muros y artesonados se conservan ejemplos de pintura mural, testigos de un interés comunicativo particular de la época basado en una iconología aún en estudio por los especialistas en la materia; por otro lado, pequeñas muestras de material cerámico de origen arqueológico proveniente de diversos territorios del actual territorio boyacense, especialmente del norte, occidente y la zona correspondiente al Valle de Tenza.

A su vez, la Casa del Escribano custodia una colección de bienes muebles de época que recopila aspectos formales, tecnológicos, estéticos y simbólicos de los siglos coloniales $X V I, X V I I$ y XVIII, como también algunos ejemplos del siglo $\mathrm{XIX}$, todos articulados entre sí en siete espacios expositivos cuyo propósito es narrar, de manera un tanto fragmentada $e$ inconexa, la cultura material de la ciudad en esas etapas de su historia. Por su parte, la colección de la Casa del Fundador está compuesta por piezas de contextualización, elaboradas en su gran mayoría durante la primera mitad del siglo $X X$, cuya función es ambientar a partir de seis áreas de exposición al estilo de los museos de este género en España y Francia - el tiempo en que vivió Gonzalo Suárez Rendón, desde sus inicios en Málaga hasta su residencia permanente en la hoy Tunja.

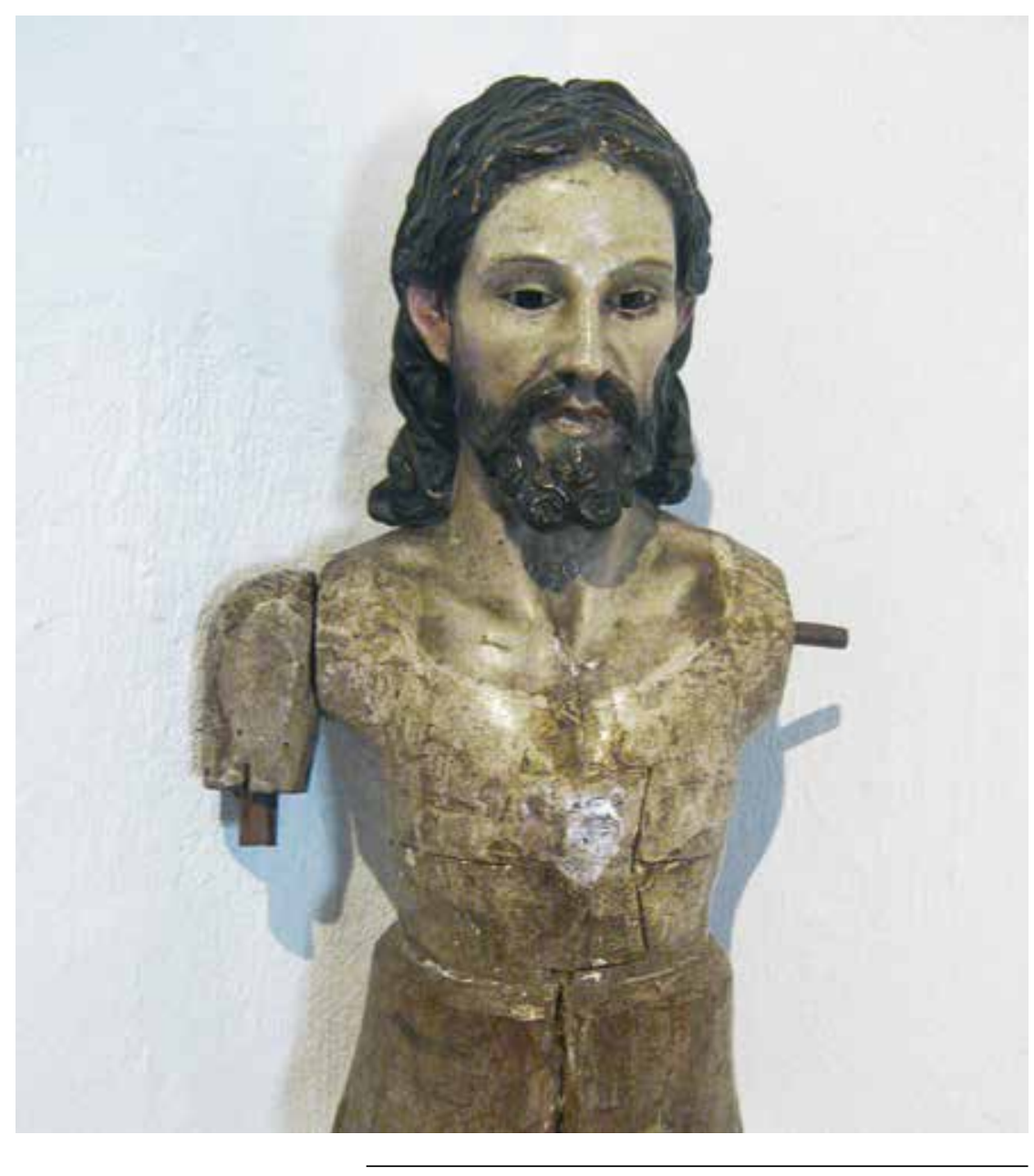

Figura 7. Imagen de vestir - colección Casa Museo del Escribano Don Juan de Vargas. Fuente: autor 
Si bien las dos colecciones persiguen el interés común de contextualizar el período colonial en Tunja y ser ejemplos de la cotidianidad hispana y criolla del Nuevo Reino de Granada, su valoración ha de basarse en criterios diferentes. Esta cuestión determina gran parte de la cuantificación y la caracterización de los riesgos que potencialmente podrían disminuir los valores culturales portados por sus acervos.

\section{VALORACIÓN DE LA}

\section{COLECCIÓN}

$\mathrm{Al}$ seguir el planteamiento metodológico propuesto para la investigación y en pro de identificar las prioridades de conservación de las colecciones de ambos casos, se hizo necesario realizar una valoración de las mismas cuyo punto de partida fuera su capacidad comunicante como dinamizador cultural en su contexto social específico (Tunja). Para esto se abordaron componentes que dan forma al discurso desde el cual se pretende jerarquizarlas en términos de importancia gramatical dentro del planteamiento expositivo, que en definitiva es el reflejo y soporte de su conceptualización, es decir, la directriz fundamental para conferirles su relevancia patrimonial en la ciudad.

Aunque ambas colecciones contienen objetos de gran valor histórico, estético y cultural, para un trabajo como el presente es preciso valorar el conjunto. Se trata de dos grupos de bienes muebles unidos gracias a dos argumentos curatoriales que direccionan ambos guiones museográficos, esto quiere decir que los objetos tienen

${ }^{9}$ Primordialmente un interés histórico motiva las visitas de los estudiantes de colegio y universidad, además de los investigadores, que en conjunto corresponden al $89.83 \%$ de los visitantes que mensualmente recorren la Casa Museo valor al aportar, como ejes articuladores, a la gramática total sobre la cual se fundamenta la dialéctica de cada exposición y la conceptualización de las colecciones.

\section{Perspectiva de valoración}

Una vez aclarada la importancia del conjunto sobre la individualidad de los objetos, identificados los intereses del público que visita las colecciones ${ }^{9}$ y reconocida la función de estas en el contexto tunjano, es pertinente indicar que su valoración partió de su significado cultural con base en su valor histórico, pues desde su planteamiento expositivo, criterios curatoriales y conceptualización, ambas se presentan bajo un 
lejana en el tiempo pero no en el espacio. Esa artificialidad se entiende como el conjunto de artefactos producidos en un contexto específico, los cuales se convierten en manifestaciones físicas de la cultura que los generó.

argumento narrativo de épocas específicas: en la Casa del Escribano Juan de Vargas, los siglos XVI, XVII y XVIII, en tanto en la Casa del Fundador Gonzalo Suárez Rendón, la segunda mitad del siglo XVI y la primera del XVII.

\section{Respecto a dicho valor, Joseph}

Ballart declara su relevancia como fundamento de colecciones. Esto es aplicable para los presentes casos de estudio, pues el objetivo de ambos es la "contextualización temporal de un fenómeno materialista determinado, bajo un interés narrativo desde sus valores mismos como documento" (Ballart, 1997, p. 20). Por su parte, Schelereth (Citado por Ballart), refuerza esta idea al mencionar que las exposiciones materiales, como son las existentes en las casas museo de Tunja, basan su importancia en el hecho de ser "puntos de contacto" donde el público reflexiona en torno a la necesidad artificial del uso objetual por parte de una cultura determinada,

El valor histórico, entendido como eje referencial del proceso de valoración, se sustenta en dos aspectos: tecnológico y estético. El primero se refiere a aquellos elementos que, relevantes para la producción del objeto como forma, obedecen a las lógicas constructivas y representativas de la época histórica en cuestión (la Colonia en Tunja). El segundo, visto como una consecuencia plástica y visual del primero, incluye aquellas características de estructura y composición formal propias de las lógicas discursivas de dicho período que develan gustos y formas de pensar.

\section{Referentes para la valoración}

Para dar soporte a la valoración y establecer su marco de referencia, es preciso recurrir a datos y revisar publicaciones que han abordado este proceso. De igual modo, se obtiene así información valiosa para dimensionar la importancia de las colecciones.

En torno al contexto de los siglos en cuestión, la mayoría de autores, tales como Magdalena Corradine, Germán Villate y Javier Ocampo, coinciden en lo expresado por Vicenta Cortés al referirse a la primera mitad del siglo XVI: "Tunja pasa a ser en un $90 \%$ española, con solo un $10 \%$ de indígenas, negros, mulatos y mestizos, que se ubicaron en la periferia del asentamiento y se dedicaban a los servicios domésticos de la gente de la ciudad" (citada por Wiesner, 2008, p. 48). La población indígena fue desplazada hacia lugares como Sora, Cucaita y Motavita, en el entorno de Farfacá y Ramiriquí (Pradilla \& Villate, 2010).

Es significativo tener en cuenta esta realidad para vislumbrar la pertinencia de los intereses conceptuales de las colecciones y sus correspondientes exposiciones en el contexto Tunja, toda vez que constituyen la evidencia material de la entrada a un espacio geográfico y de su posesión por parte de una sociedad de raíces europeas que desplazó a los tradicionales habitantes nativos del otrora "Cercado Grande de 
los Santuarios", es decir, la antigua Hunza para el mundo Muisca (Pradilla \& Villate, 2010).

Esa apropiación española dio como resultado un cambio de uso del lugar. Se reemplazaron los significantes y significados; se construyeron templos, conventos e iglesias sobre los cercados de los jefes indígenas; se modificaron las lógicas ritualistas; la figura de Cristo adoptó el papel primordial en sustitución de Goranchacha; la celebración litúrgica y los monasterios tomaron el lugar de las antiguas "cucas", y así podrían seguirse enumerando las transformaciones. En este punto cabe resaltar que exposiciones como las presentadas por las casas museo no tendrían la misma incidencia y relevancia en otro punto geográfico, pues su valor no solo radica en la materialidad de los objetos integrantes sino también en su articulación contextual, al ser evidencias de procesos vividos por territorios específicos.
En ambos casos la pintura mural es lo más valioso, pues no solo son las únicas piezas originales del edificio sino que también constituyen un referente del público visitante y un contexto sociocultural. Además, han sido los componentes más estudiados desde hace varias décadas por los especialistas: Enrique Marco Dorta (1957), Carlos Arbeláez Camacho y Santiago Sebastián (1967), Javier Ocampo López (1970), Francisco Gil Tovar y Jorge Rueda (1983), Germán Tellez (1995), Gustavo Mateus (1995) y José Miguel Morales Folguera (1998). Los investigadores coinciden en que se trata de uno de los ejemplos más sobresalientes de este género pictórico en la arquitectura civil del período colonial en el Nuevo Reino de Granada.

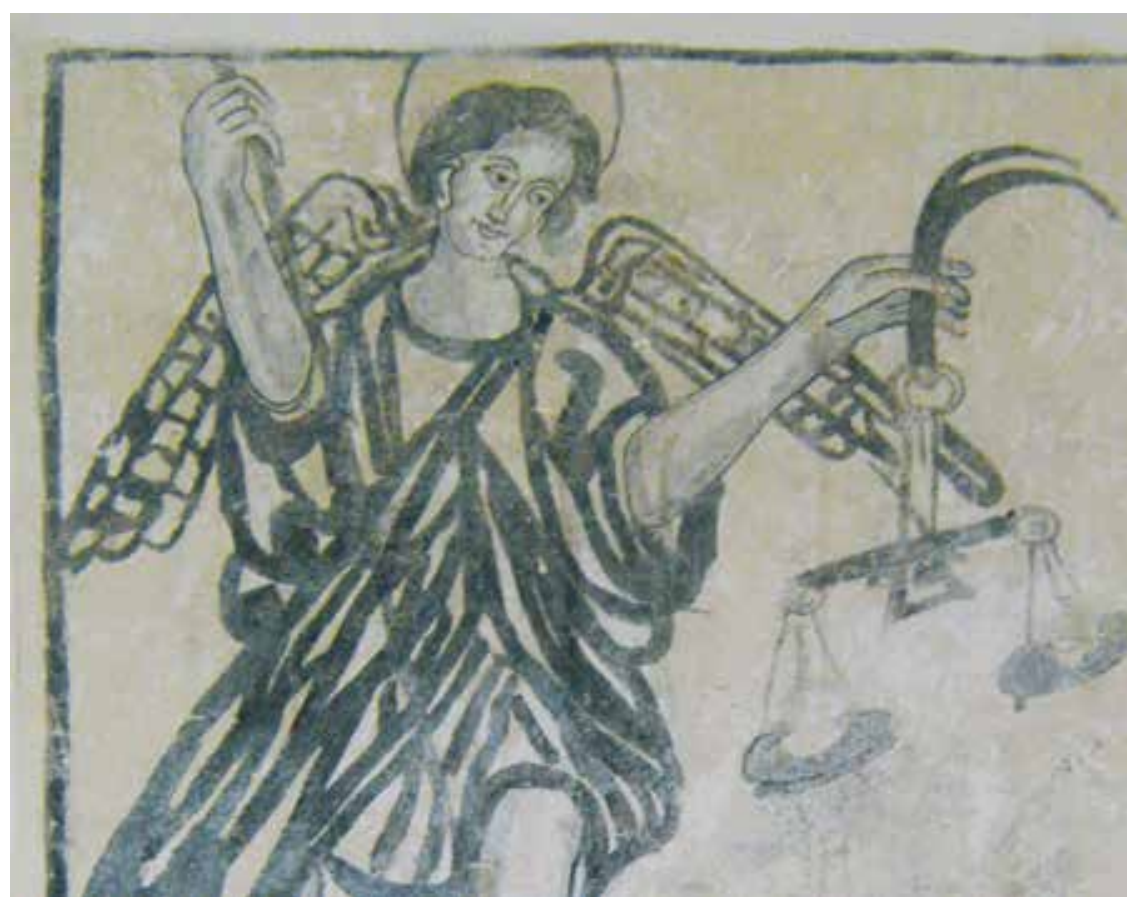

Figura 8. Pintura mural - Casa del Escribano Don Juan de Vargas. Fuente: autor 
Para los demás bienes muebles se marca una distancia considerable entre los dos museos. La Casa del Escribano custodia objetos originales elaborados durante la Colonia, en tanto la Casa del Fundador construye su narrativa a través de reproducciones contemporáneas que retoman elementos formales, tecnológicos y estéticos para generar ambientes de contextualización. Esta diferencia incide en el comportamiento de la escala de valor, básicamente porque para el primer caso las órbitas de valoración gravitan en torno a

\section{Criterios de valoración}

Las colecciones tienen una función cultural en el contexto tunjano como referentes simbólicos de la sociedad y partes activas dentro del imaginario colectivo. Además, su interés por contextualizar una época específica, comprendida por los siglos $\mathrm{XVI}$, XVII y XVIII, significa un aporte para la comprensión de las bases que soportan gran parte de la forma de pensar enraizada en la cultura tunjana. Como lo plantea Fichter (1994), la cultura no nace de forma natural con el hombre sino que se enseña y se aprende, "el individuo la deriva de sus antepasados (...) la cultura interpreta los valores de la sociedad de modo que la gente reconoce y apropia lo que tiene valor (...) Cada cultura se identifica desde su sistema de significantes y significados" (p. 37). Dicho sistema, a fin de cuentas, es el núcleo fundamental de valores.

Dentro de esa función cultural, la Teoría del conocimiento histórico ofrece otro fundamento para los criterios de valoración. La Historia tiene con la cultura un nexo más íntimo e indestructible que otras disciplinas: "La Historia es la ciencia más dependiente de todas. Ella precisa más que otra ninguna de continuos auxilios y apoyos de otras muchas ciencias para formar nociones, para fijar sus normas, para llenar sus fondos" (Sperber, 1988, p. 9).

En relación con la dependencia de la ciencia histórica en el contexto puntual de Tunja, Magdalena Corradine (2009) destaca la colección de la Casa del Escribano como una de las pocas en la ciudad que "permiten interpretar el pasado de la misma desde los vestigios materiales, ya que la historia no es nunca un reflejo mecánico del pasado sino una interpretación del mismo que requiere de puntos referenciales" (p. 43).

De la apreciación de Corradine se desprende otro elemento para ser articulado con la función cultural de las colecciones en cuestión. Es la idea de estas como parte de lo denominado por Sperber (1988) "organismo histórico", pues ambas casas son eslabones representativos que permiten configurar, junto con las iglesias y los otros museos de la capital boyacense - validados, habitados y dinamizados por la ciuda- 
danía-, "La representación de un organismo histórico vivo como condición necesaria no solo para poder aplicar el concepto de evolución, sino también en general para entender las formas de la sociedad, sea en el presente, sea en el pasado" (p. 69). Para la sociedad tunjana ambos son significantes culturales que posibilitan.

La aspiración de una cultura a entender el sentido de su pasado y dar a este una forma (...) el hombre como tal, en su aislamiento, no es nunca fenómeno histórico, es solamente unidad biológica. Unidad histórica y cultural solo viene a ser en su posición en la vida, en su conexión con su medio ambiente, con su tiempo, en el curso de su destino (Sperber, 1988, p. 73).

\section{IDENTIFICACIÓN, ANÁLISIS Y}

\section{EVALUACIÓN DE RIESGOS}

Para la identificación de los riesgos que podrían afectar las colecciones fue necesario, ante todo, reconocer el comportamiento, el alcance y la aplicación al caso de Tunja de los 10 agentes de deterioro propuestos por el ICC, para analizar su incidencia en las instituciones. Luego, se evaluaron los peligros detectados a través de la construcción de escenarios de riesgo proyectados a 100 años. Así, se encontró que el agente más preocupante para ambos casos es el fuego, entre cuyas causas es posible enumerar: deficientes sistemas eléctricos, con cables descubiertos en contacto directo con tensores, vigas y elementos de madera; ausencia de dispositivos de seguridad contra incendio; y las propias colecciones, pues en un $95 \%$ se componen de objetos constituidos por materiales altamente inflamables (madera, tela y papel). Una conflagración podría consumirlas rápidamente y dejar pérdidas irrecuperables, situación que demuestra la perentoriedad de reforzar los planes de atención y prevención de desastres en las dos casas con el fin de mitigar esta amenaza.

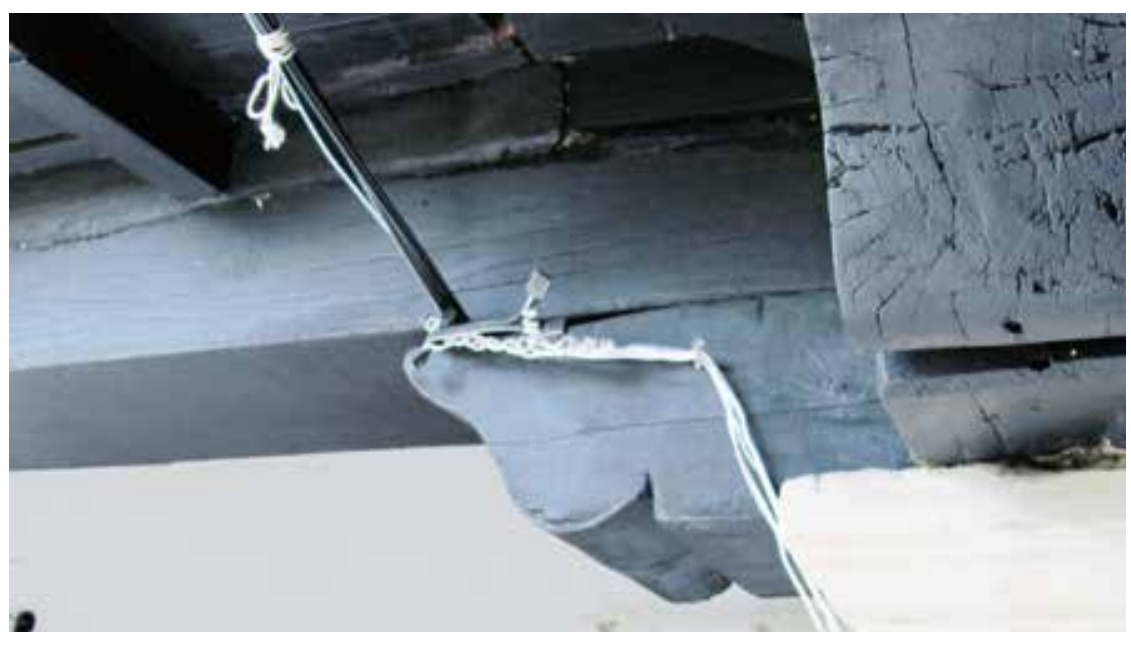

En orden de prioridad aparece a continuación el asente denominado por el ICC como disociación. Este demarca un horizonte de riesgo que no afecta directamente la materialidad sino que concentra la disminución de valor del conjunto por ausencia o deficiente articulación de los objetos dentro del diálogo expositivo. En los casos de estudio, la falta de un inventario de la colección, en los términos recomendados por el grupo de patrimonio cultural mueble de la Dirección de Patrimonio Cultural del 
10 Para el momento de la implementación de la Metodología de Gestión de Riesgos de Colecciones en la Casa del Fundador, este museo no contaba con un guion museográfico que hiciera uso de la colección de manera acorde con sus potencialidades. Posteriormente, con base en los resultados de la investigación desarrollada, se decidió elaborar un nuevo guion para las salas permanentes, como parte del cumplimiento del Plan de Acción para la Gestión de Riessos de Colecciones de esta Casa Museo, documento resultante de la investigación.
Ministerio de Cultura, ha conllevado a concebir las colecciones como parte del listado de almacén manejado por la entidad custodia (Alcaldía Mayor de Tunja). Esto pone en evidencia la alta probabilidad de pérdida de objetos por deterioro, pues no se cuenta con un sistema integral para garantizar la recuperación y el mantenimiento de los valores, lo cual trae consecuencias negativas para la estrategia museográfica.

En la Casa Museo del Fundador se observó un potencial peligro adicional que atenta contra el sistema integral de valor: disminución de los valores de los objetos por falta de articulación efectiva en la dialéctica discursiva de la exposición. Esta problemática ha sido motivada por la pérdida total de la lógica expositiva, tras décadas de malos manejos en las salas que rompieron la articulación entre las piezas. Además, se incorporaron objetos nuevos sin relación alguna con los intereses narrativos originales, convirtiendo la exposición en una suma sin criterio gramatical ni lógicas espaciales ${ }^{10}$.

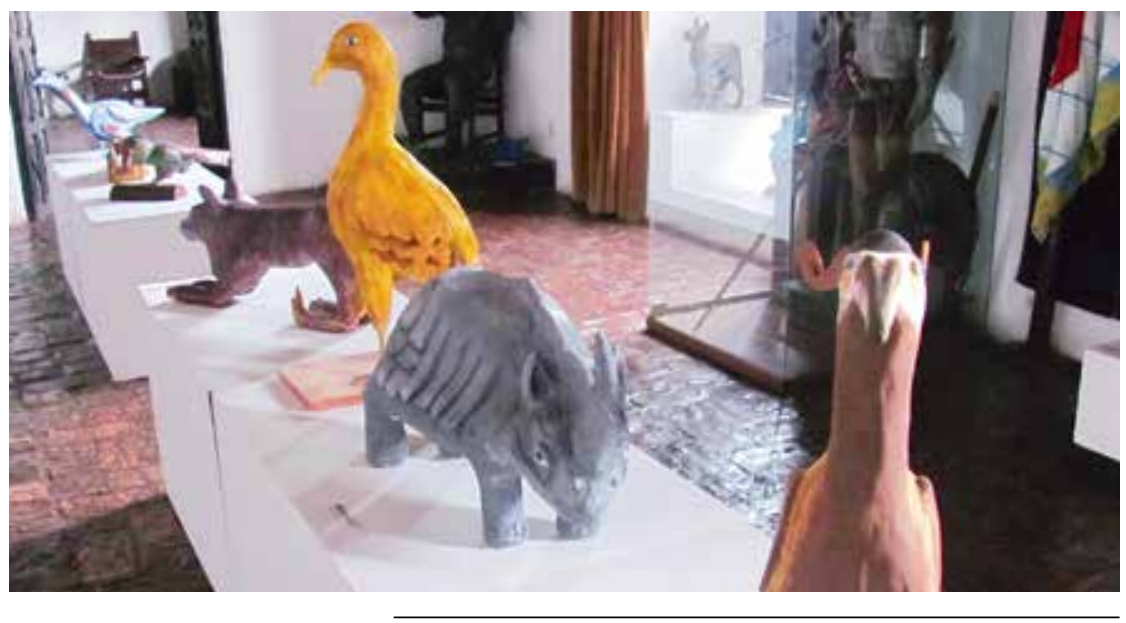

Figura 10. Riesso de disociación por intervención temporal - Casa del Fundador. Fuente: autor

Los riesgos derivados del agente disociación hacen indispensable un registro legal de las colecciones que obligue al custodio a mantener un sistema ordenado para la conservación de los objetos, de manera consecuente con su importancia patrimonial. En el caso de la Casa del Fundador se adiciona la necesidad de construir un nuevo 
guion museográfico que propenda por la articulación efectiva entre los objetos a partir de una conceptualización destinada a rescatar las exigencias discursivas del conjunto.

Se encuentran luego los riesgos asociados a robos y vandalismo. Este agente coincide en ambos casos, pues las salas son vulnerables ante actos vandálicos que atenten contra la materialidad de los objetos o conduzcan a su pérdida. Esto se debe, principalmente, a problemas de seguridad y protocolo para el manejo de visitantes, a los vacíos en la reglamentación para su ingreso a los espacios de exhibición y a la ausencia de mecanismos orientados a su formación. Por lo tanto, es procedente reforzar los programas de seguridad, diseñar estrategias museográficas y trabajo con públicos para garantizar la salvaguarda de las colecciones.

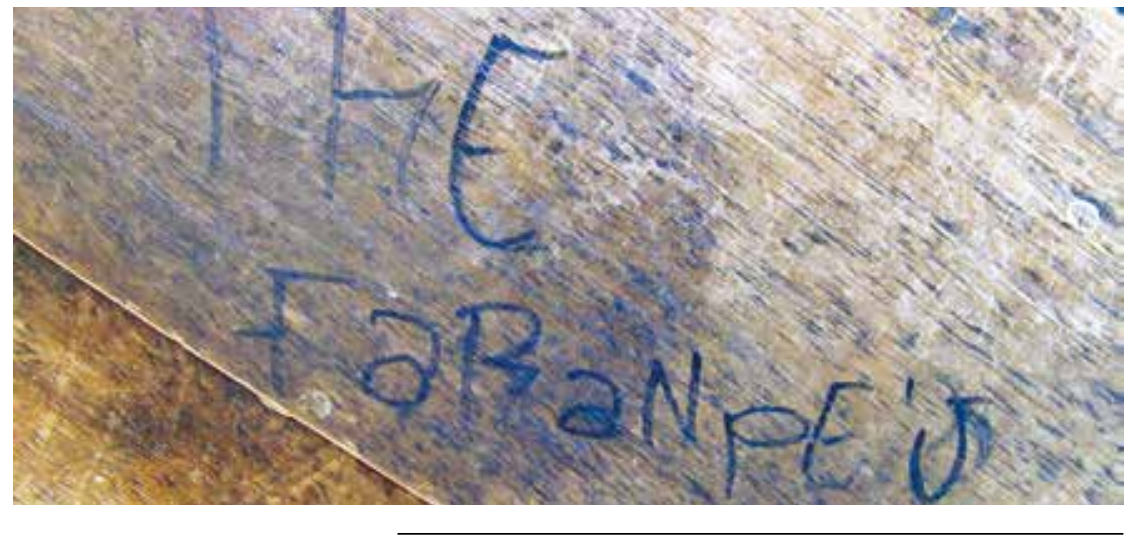

Figura 11. Vandalismo - colección de la Casa del Fundador. Fuente: autor

Este primer grupo de prioridades es cerrado por los riesgos asociados al agente fuerzas físicas. Se trata de un potencial peligro para la pintura mural y la estabilidad de los edificios, pues el subsuelo de Tunja es inestable debido a sus características sedimentarias, realidad preocupante si se relaciona con la ubicación de la ciudad en una zona de alta probabilidad sísmica. A la Casa del Fundador se suma el problema de las hondas de alta frecuencia producidas por los eventos realizados en la Plaza de Bolívar, las cuales ejercen fuerzas negativas de carácter acumulativo que generan tensiones diferenciales en la pintura mural del costado occidental del artesonado. De esta forma se crean sistemas de grietas y fisuras que con el tiempo pueden producir desprendimiento de fragmentos y su eventual pérdida total por choque y pulverización.

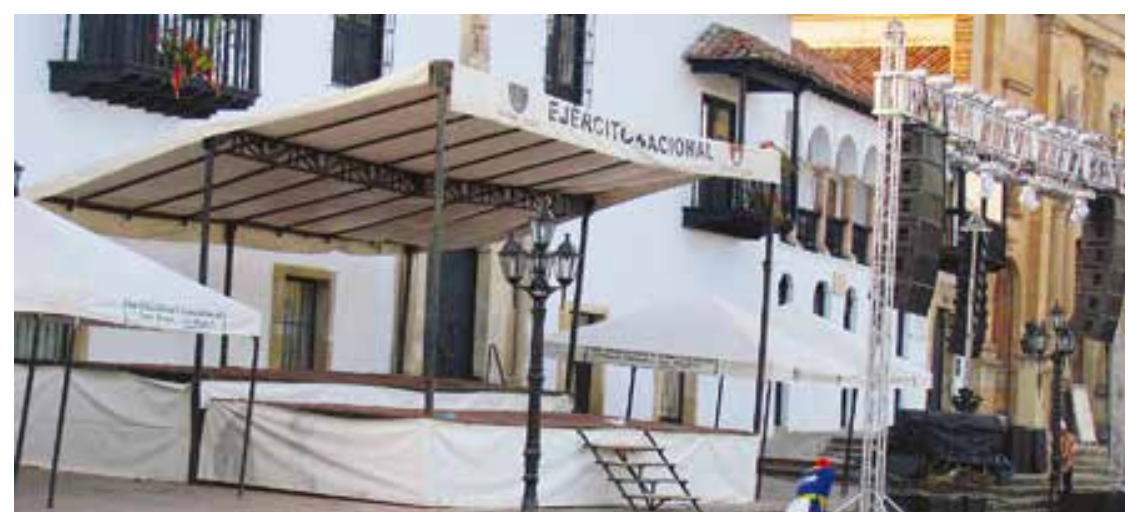

Figura 12. Riesgo por fuerzas físicas en la Casa del Fundador. Fuente: autor 
Un segundo grupo reúne agentes no tan preocupantes como los anteriores, aunque factibles de generar problemas a largo plazo si no se bloquean las posibilidades de su aparición. En orden de importancia, estos son la humedad relativa incorrecta y las plagas. En relación con este último, el mantenimiento periódico de la colección de la Casa del Escribano ha hecho la diferencia, pues el retiro constante de la suciedad en las superficies de las piezas y los sistemas de exhibición (vitrinas y estantes), ha evitado el

surgimiento de agentes fúngicos y demás amenazas biológicas. La situación es distinta en la Casa del Fundador. Allí, la falta de mantenimiento recurrente en el interior de las vitrinas ha generado microclimas que sumados a la alta higroscopicidad del polvo acumulado, ha ocasionado en algunos textiles el surgimiento de agentes como el aspergillus, identificado en diferentes

estados vegetativos, cuya presencia afecta la estabilidad de las piezas. Esto demuestra la necesidad de implementar un programa de conservación enfocado en neutralizar las amenazas a partir de actividades puntuales de intervención en los objetos y del control ambiental de los espacios de depósito y exhibición.

El tercer y último grupo reúne tres agentes que no generan mayor preocupación, pues sus riesgos afectarían una mínima porción del valor total de la colección. Son amenazas a largo plazo, fácilmente controlables y cuyos efectos podrían ser reversibles a partir de acciones básicas de conservación. Se trata de los contaminantes, la luz y el agua. El primero perjudica por igual a ambos museos al ocultar valores tonales de la pintura mural. Los problemas vinculados con el segundo generan situaciones diversas: en la Casa del Escribano el impacto se manifiesta en el deterioro de algunos objetos por contacto directo con rayos de luz natural que debilitan y decoloran las fibras de determinados muebles, en tanto en la Casa del Fundador la disminución de valor se manifiesta en las dificultades para apreciar correctamente la estética de ciertas piezas - con la consecuente disminución de la capacidad expresiva de la exposición - como resultado del deficiente sistema de iluminación.

\section{CONCLUSIONES}

\section{La Casa del Escribano Don Juan de Vargas y la Casa del Fundador} Gonzalo Suárez Rendón son las instituciones museísticas más importantes del centro tradicional de Tunja ya que sus características arquitectónicas y los bienes muebles integrantes de su colección les permiten mantener vigente la memoria histórica de la ciudad. Por consiguiente, su salvaguarda y protección es una labor fundamental para el fortalecimiento de la identidad tunjana y boyacense.

La valoración de las colecciones de bienes muebles de ambos casos de estudio muestra que, a pesar de estar configurados por piezas de distintas órbitas de valor, constituyen sistemas articulados de objetos portadores de valores formales, tecnológicos, históricos, estéticos y simbólicos que sustentan su inclusión y se validan dentro de 
la capacidad discursiva del conjunto.

Cualquier alteración causada por una pérdida, bien sea total o parcial de esos valores, trae consigo una disminución en la capacidad comunicativa de la colección, en su condición de insumo para el planteamiento de argumentos expositivos o de detonante para problemas de investigación.

La Gestión de Riesgos de colecciones es un "método" efectivo que desde la conservación preventiva permite reconocer con precisión las posibles amenazas para la unidad y la permanencia de esos conjuntos de valores.

Su aplicación permite diseñar estrategias destinadas a bloquear los riesgos $y$ mitigar sus posibles efectos, sin caer en especulaciones causantes de excesos u omisiones.

El paso propuesto para la valoración de las colecciones demuestra la complejidad y a la vez la utilidad de realizar esta labor con el fin de cuantificar los porcentajes de valor de los objetos y posibilitar la operatividad del sistema metodológico en sus fases posteriores. La valoración realizada en ambos casos también ejemplifica la posibilidad constante de llegar a resultados que incurren en sesgos, los cuales deben ser identificados y manejados de manera adecuada para que no interfieran en los intereses específicos del análisis requerido.

El trabajo de identificación, análisis y evaluación de los riesgos, a pesar de haber sido planteado en tres fases diferentes, presenta flujos de información e insumos reflexivos que impiden su clara separación en campo. Por tal motivo, es pertinente continuar con un planteamiento metodológico de pasos separados pero con una constante y necesaria interrelación.

Aunque se trata de dos colecciones protegidas y preservadas de manera incipiente y en gran medida empírica, la investigación realizada ha evidenciado la urgencia de construir los correspondientes planes de acción para la gestión de riesgos, a partir de una perspectiva institucional basada en la conservación preventiva, actualizada y en sintonía con las dinámicas museísticas contemporáneas. Según lo observado es fundamental enfilar acciones, en primera instancia, hacia la prevención de desastres, la seguridad de los objetos, el registro legal y la reglamentación para su manejo. Posteriormente se continuaría con la readecuación de los espacios de depósito, la corrección de sus problemáticas de conservación, la evaluación e intervención de los sistemas de exhibición en sala.

En términos de conservación, la situación de los casos de estudio está por encima del promedio de la mayoría de instituciones museísticas regionales en el país.

Dada esta realidad, se puede deducir que el patrimonio mueble en Colombia sigue en peligro de desaparecer por falta de un compromiso real tanto de los custodios -en términos de conocer, entender y dar un manejo adecuado a las colecciones- 
como de los estamentos gubernamentales en lo concerniente a la construcción de políticas culturales públicas que, acordes con la realidad nacional, faciliten herramientas para fortalecer la salvaguarda integral de la memoria material. De no asumirse esa responsabilidad, se continuará con "museos-bodega" donde se almacenan bienes subvalorados, sin estudio y cuya capacidad comunicativa se pierde progresivamente por el deterioro incontrolable de su materialidad.

Para que la preservación de una colección sea efectiva en términos de conservación preventiva, se requiere un trabajo interdisciplinario que articule la

Ballart, J. (1997). El patrimonio histórico y arqueológico: valor y uso. Recuperado de http://books.google.com.co/books/about/El_patrimonio_hist\%C3\%B3rico_y_ arqueol\%C3\%B3 gico.html?id=HXNW8RwMdbkC\&redir_esc=y

56 intervención con los aportes de personal tanto interno como externo. Solo de esta manera se puede garantizar la sincronía del proceso y su existencia dinámica institucional, elementos fundamentales para la efectividad de las acciones en procura de la estabilidad y la permanencia de los valores sobre los que se fundamenta la importancia patrimonial de los objetos.

Cardona, O. (2001). La necesidad de repensar de manera holística los conceptos de vulnerabilidad y riesgo. Una crítica y una revisión necesaria para la gestión. Bogotá: Centro de Estudios sobre Desastres y Riesgos de la Universidad de los Andes.

Corradine, M. (2009). Los Fundadores de Tunja. Tunja: Secretaría de Cultura y Turismo de Boyacá.

Corradine, M. (2009). Vecinos y Moradores de Tunja 1620 - 1623. Tunja: Gobernación de Boyacá. 
Fichter, J. (1994). Sociología, pautas de conducta. Barcelona: Herder.

Garnica García, I. (2010). La Conservación y sus inquietudes acerca de los últimos parámetros sobre normas ambientales. Parte II. Argentina: INTI - Celulosa y Papel.

Mateus, G. (1995). Tunja, Guía Histórica del Arte y la Arquitectura. Bogotá: Gúmaco Ediciones.

Michalski, S. (2009) Preservación de colecciones. Instituto Canadiense de Conservación.

Pradilla, H. \& Villate, G. (2010). Catálogo de pictografías, moyas y rocas del Farfacá de Tunja y Motavita, Boyacá (Colombia). Tunja: Universidad Pedagógica y Tecnológica de Colombia.

Salas, I. (2005). El debate entre una fundamentación Ontológico-Hermenéutica y una fundamentación Pragmática-Trascendental. Lectura de los textos principales de la obra de Gadamer y Apel. Tesis de Maestría en Filosofía, Universidad de Chile.

Sperber, D. (1988). El Simbolismo en general. Barcelona: Editorial Anthropos.

Wiesner, L. (2008). Tunja, ciudad y poder en el Sig/o XVII. Tunja: Universidad Pedagógica y Tecnológica de Colombia. 